\title{
Proximity heating of CFRTP molding dies by using high-frequency direct current
}

\author{
K. Tanaka, R. Sue, K. Iwamoto \& T. Katayama \\ Department of Biomedical Engineering, Doshisha University, Japan
}

\begin{abstract}
In the automobile industry, it is required to reduce the weight of cars for better fuel consumption. Recently, Carbon Fiber Reinforced Thermoplastics (CFRTP) are expected to be used for lightweight component parts. However, the cost of CFRTP is so high that the use of CFRTP is barely applied in the automobile industry. In order to lower the cost of CFRTP, simple equipment and low consumed power are necessary. High-frequency direct resistance heating to CFRTP molding dies becomes possible to solve these issues. High-frequency direct resistance heating is a method that alternating current is directly applied to a metal, and metal surface is heated by skin effect. When opposite directions of an alternating current flow in a pair of metal sections which face each other with a small gap, the proximity effect also promotes the concentration of current density on proximal surfaces of the metal and heats the metal surface intensively by joule heat. By applying high-frequency direct resistance heating to CFRTP molding, cost reduction as well as simplification of the facilities can be expected. In this study, in order to apply high-frequency direct resistance heating to CFRTP molding die, the effects of the proximity effect on the mold are evaluated to clarify the heating characteristics and conditions of the proximity effect, and the applicability of CFRTP molding is discussed. The experimental result reveals that the proximal surfaces can be heated by proximity effect.

Keywords: die heating, proximity effect, high-frequency direct resistance heating, carbon fiber reinforced thermoplastics.
\end{abstract}

\section{Introduction}

Out of consideration for environmental issues, the lightening of various transportation equipment has been required [1-3]. Expectations for Carbon Fiber 
Reinforced Plastics (CFRP) have been raised in the aerospace and the automotive industry. In particular, considering recyclability and productivity, it is desirable to apply Carbon Fiber Reinforced Thermoplastics (CFRTP) that are using thermoplastic resin for the matrix [4]. However, the cost of CFRTP is so high that CFRTP have not yet led to full-scale application in the automobile industry.

In order to lower the cost of CFRTP, developments of both novel molding methods and novel materials are required. In this study, the development of new molding method is focused on. Recently, high-speed compression molding process of CFRTP by means of electromagnetic induction heating system was proposed [5-7]. In this system, when a heat targets become larger, necessary coils surrounding a molding die also become larger. This makes the equipment more complicated and the production cost becomes higher. To reduce the cost of production, another system without complicated equipment is expected to be developed.

For a heating technique that is to be applied for metal heating, heat treatment and welding, we have high-frequency direct resistance heating and electromagnetic induction heating [8-10]. High-frequency direct resistance heating has advantages in terms of simple equipment and low consumed power. High-frequency direct resistance heating is a method that alternating current is directly applied to a metal, and the metal surface is heated by skin effect. As illustrated in fig. 1, when directions of an alternating current flow in a pair of metal sections which face each other with small gap, the proximity effect also promotes the concentration of current density on proximal surfaces of the metal. The skin effect and the proximity effect are induced by the magnetic field resulting from the high-frequency alternating current. Thus, only the metal surfaces are heated by joule heat. By applying high-frequency direct resistance heating to CFRTP molding, cost reduction as well as simplification of the equipment and facilities can be expected.

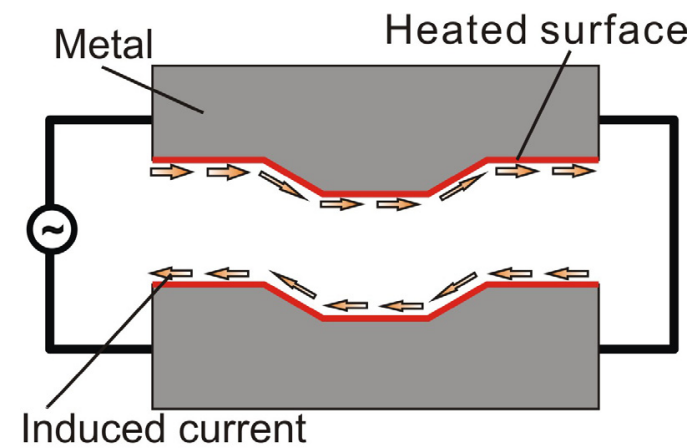

Figure 1: Schematic drawing of direct resistance heating. 
In this study, in order to apply high-frequency direct resistance heating to CFRTP molding die, the effects of the proximity effect on the mold are evaluated to clarify the heating characteristics and conditions of the proximity effect, and the applicability of CFRTP molding is discussed.

\section{Experimental methods}

Figure 2 is a cross section view of the experiment system. The vacuum-tube oscillator with $30 \mathrm{~kW}$ maximum output and $185 \mathrm{kHz}$ current frequency was used as the high-frequency power supplier. Carbon steel of Type S50C which has a mold-quality with a high magnetic permeability was used as the mold material. The Teflon sheet was inserted between the molds as an electrical insulations, and molds end was connected by electrodes. K-type thermocouples were fitted on six places and the temperatures per second were recorded with graphic recorder. The power was applied to the molds until the temperature of inner surfaces reached $150^{\circ} \mathrm{C}$. After that, the mold was naturally cooled. In this study, in order to clarify the influence of the oscillator output and the gap among the molds on the proximity effect, experiments were conducted by which power output of the oscillator was set at $1.0 \mathrm{~kW}$ and $4.8 \mathrm{~kW}$, and the gap among the molds was set at $2 \mathrm{~mm}, 5 \mathrm{~mm}$ and $8 \mathrm{~mm}$.

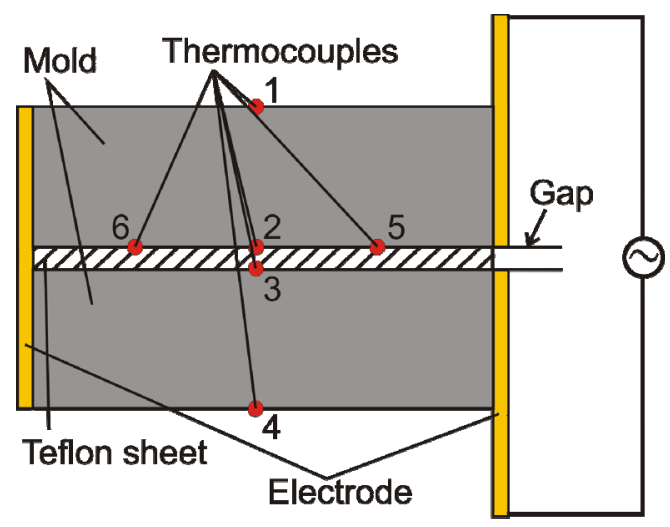

Figure 2: Schematic drawing of experimental system.

\section{Results and discussion}

Figure 3 shows temperature histories of molds having the gap of $2 \mathrm{~mm}$ when power output of the oscillator was $1.0 \mathrm{~kW}$. Under the condition of $1.0 \mathrm{~kW}$, it took about 120 seconds that the temperature of inner surfaces was heated to $150^{\circ} \mathrm{C}$. At this time, the temperature difference between high temperature area (Points 2 and 3 ) and low temperature area (Points 1 and 4) was about $40-60^{\circ} \mathrm{C}$. The temperatures of inner surfaces (Points 2 and 3 in fig. 3) were much higher than outer surfaces (Points 1 and 4). The initial slope of the temperature history curve 
(Points 1 and 4 in fig. 3) in non-proximal surfaces was zero, so the current did not flow through non-proximal surfaces. Therefore, it is also considered that the temperature rise in the non-proximal surface was due to heat transfer from the inner surface where the temperature was high.

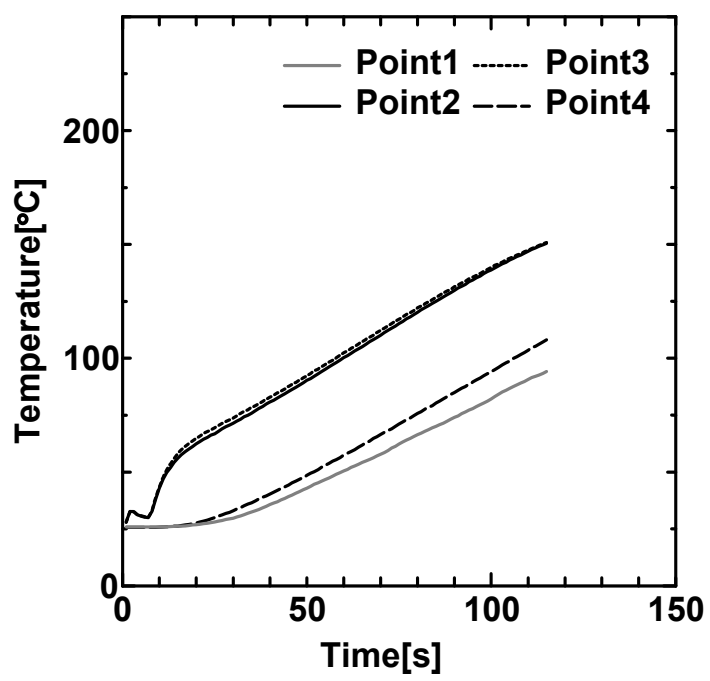

Figure 3: Temperature history of heated mold with $1.0 \mathrm{~kW}$ output (gap=2m).

Figures 4 and 5 show temperature histories when temperature of Point 2 was heated to $150^{\circ} \mathrm{C}$ under the condition of $1.0 \mathrm{~kW}$ and $4.8 \mathrm{~kW}$ for the power output of the oscillator. Significant temperature rise was observed at Points 2, 5, 6 immediately after applying the power. For the condition of $1.0 \mathrm{~kW}$ it took 102 seconds to reach $150{ }^{\circ} \mathrm{C}$, on the other hand it took only 31 seconds for the condition of $4.8 \mathrm{~kW}$. Higher power supply offers faster heating. When temperature of Point 2 was heated to $150{ }^{\circ} \mathrm{C}$, temperature difference at the inner surfaces (Points $2,5,6$ ) was $6^{\circ} \mathrm{C}$ under the condition of 1 ; on the other hand it was $34^{\circ} \mathrm{C}$ under the condition of 4 . In order to apply the direct resistance heating to the CFRTP molding, uniformity of the temperature of the mold surfaces is needed. Therefore, optimum heating rate exists against allowable temperature distribution.

Figures 6 and 7 show temperature histories with the gaps of $5 \mathrm{~mm}$ and $8 \mathrm{~mm}$ between the facing molds. The results for the gap of $2 \mathrm{~mm}$ was shown in Fig. 4 . It took 102,117 and 132 seconds to reach $150^{\circ} \mathrm{C}$ for the mold with $2 \mathrm{~mm}, 5 \mathrm{~mm}$ and $8 \mathrm{~mm}$ of the gaps respectively. The gap became larger, the time to reach $150^{\circ} \mathrm{C}$ took larger. Temperature rises were also observed at the Point 1 for the results with the gap of 5 and $8 \mathrm{~mm}$ and temperature differences against Points 2, 5, 6 were small compared to the results for the gap of $2 \mathrm{~mm}$. The proximity effect becomes weaker when the gap is larger. Proximity effect is a phenomenon 


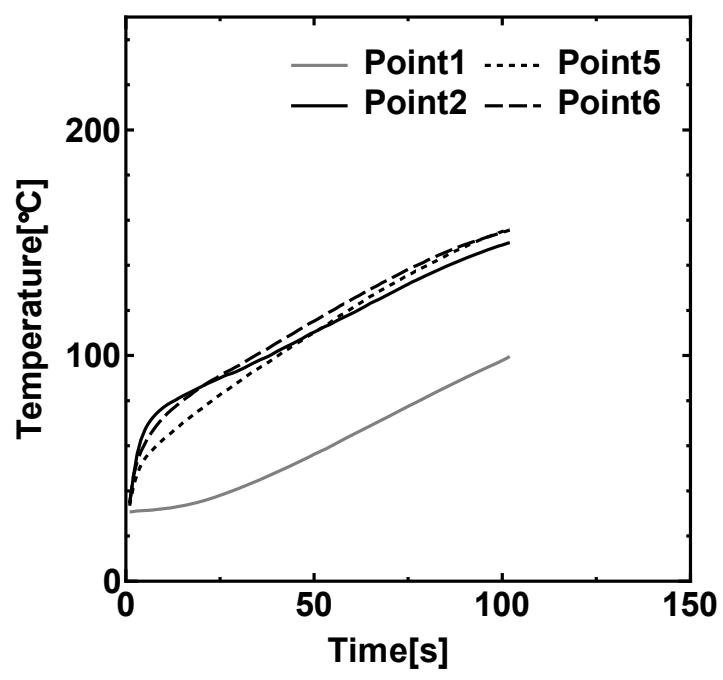

Figure 4: Temperature history of heated mold with $1.0 \mathrm{~kW}$ output (gap=2mm).

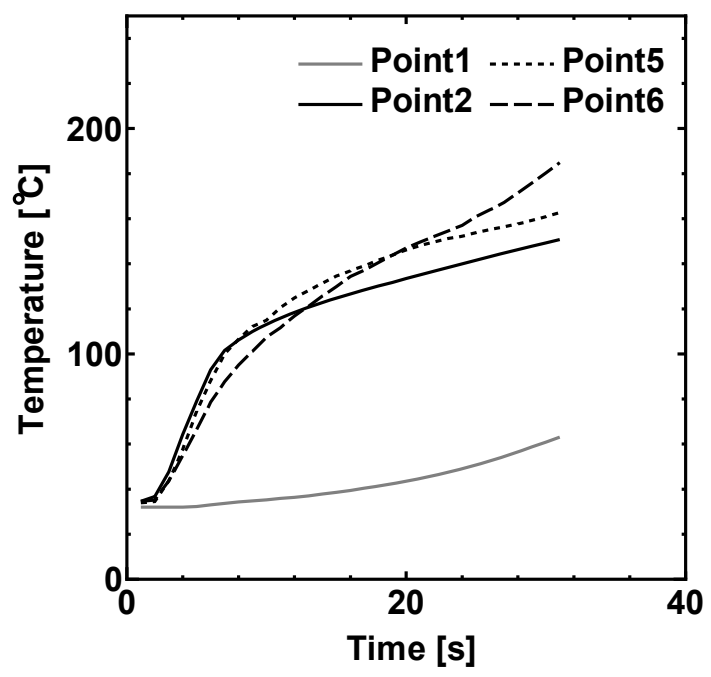

Figure 5: Temperature history of heated mold with $4.8 \mathrm{~kW}$ output (gap=2mm). 


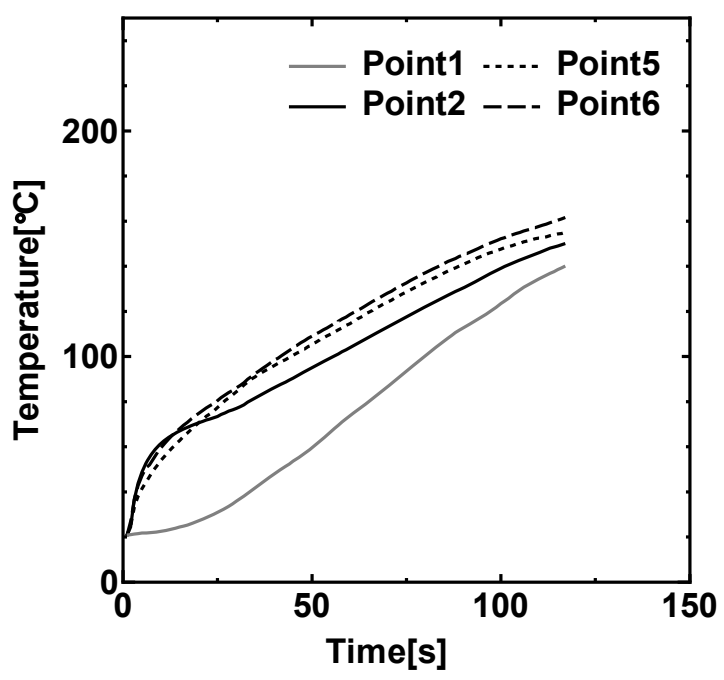

Figure 6: Temperature history of heated mold with 1.0kW output (gap=5mm).

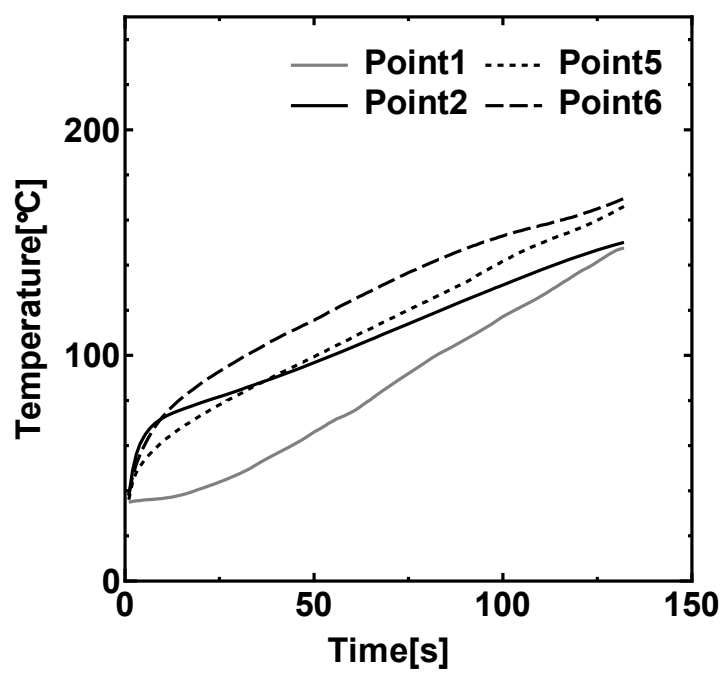

Figure 7: Temperature history of heated mold with $1.0 \mathrm{~kW}$ output (gap=8mm). 
that by the influence of the magnetic field generated by a current flowing through each mold, current density is concentrated on the proximal surface. It is considered that the proximity effect was weakened because magnetic field, affected with each other, was weakened with the widened gap between the facing molds. From these results, in the case of molding CFRTP by using direct resistance heating, it is necessary to consider the thickness of formed product.

\section{Conclusion}

Heating properties of the mold by using direct resistance heating were evaluated for the development of CFRTP molding technique. To clarify the heating properties of the mold by proximity effect, temperature histories for the molds with different gaps between facing molds were evaluated. The investigation yielded the following conclusions:

1. The temperature of the proximal surfaces of the molds tends to rise by proximity effect.

2. Because of temperature irregularity at fast heating, it is necessary to optimize the heating rate by taking allowable temperature distribution into account.

3. The smaller the gap between the facing molds, the more remarkable proximity effect was observed and temperature of the surface of the molds rises much faster.

\section{Acknowledgements}

This work was partially supported by a research project on "Research and Development Center for Advanced Composite Materials" of Doshisha University and MEXT (the Ministry of Education, Culture, Sports, Science and Technology, Japan) - Supported Program for the Strategic Research Foundation at Private Universities, 2013-2017, the project S1311036.

\section{References}

[1] Y. Daisho, Perspectives on Future Motor Vehicle Technologies Associated with Environment and Energy, IATSS Review, Vol. 33, No. 3, pp. 51-56, 2008.

[2] P. Feraboli, A. Masini, L. Taraborrelli and A. Pivetti, Integrated development of CFRP structures for a topless high performance vehicle, Composite Structures, 78, pp. 495-506, 2007.

[3] R. Shida, K. Tsumuraya, S. Nakatsuka and J. Takahashi, Effect of automobile lightening by CFRP on the world energy saving, The Ninth Japan International SAMPE symposium, pp. 8-13, 2005. 
[4] E. M. Silverman and W. C. Forbes, Cost analysis of thermoplastic composites processing methods for spacecraft structures, SAMPE Journal, Vol. 26, No. 6, pp. 9-15, 1990.

[5] K. Tanaka, T. Katsura, Y. Kinoshita, T. Katayama and K. Uno, Mechanical Property of Jute Fabric Reinforced Thermoplastics Moulded by High-speed Processing using Electromagnetic Induction, WIT Transaction on the Built Environment, Vol. 97, pp. 211-219, 2008.

[6] K. Tanaka, N. Kohashi, Y. Kinoshita, T. Katayama and K. Uno, Compression Molding of Carbon Fiber Reinforced Thermoplastics Using Non-Woven Stitched Multi-Axial Cloth by Means of Induction Heating System, Journal of the Society of Materials Science, Japan, Vol. 58, No. 7, pp. 642-648, 2009.

[7] K. Tanaka, M. Yamada, N. Kohashi and T. Katayama, High-speed Compression Moulding of CFRTP/AFRTP Hybrid Composites using an Electromagnetic Induction Heating System, WIT Transactions on the Built Environment, Vol. 112, pp. 141-151, 2010.

[8] K. Hamada, K. Isaka, D. Doi, Y. Yonemitsu and S. Iwasaki, Application of the Direct Resistance Heating for Stainless Steel/Aluminum Clad Manufacturing Process, The Iron and Steel Institute of Japan (ISIJ), Vol. 88, No. 2, pp. 16-22, 2002.

[9] M. Ishiguro, S. Maki and K. Mori, Improvement of product strength and press formability of $\mathrm{Al}-\mathrm{Mg}-\mathrm{Si}$ alloy sheets by resistance heat treatment and artificial aging, Journal of Japan Institute of Light Metals, Vol. 56, No. 6, pp. 313-316, 2006.

[10] Q. Yuan, M. Hou, Y. M. Mai and L. Ye, Resistance Welding of Carbon Fiber Reinforced Polyetherimide Composite, Journal of Thermoplastics Composite Materials, Vol. 14, pp. 2-19, 2001. 